\title{
5. The information systems discipline in New South Wales universities
}

\author{
Jim Underwood \\ Department of Information Systems \\ University of Technology, Sydney \\ Ernie Jordan \\ Graduate School of Management \\ Macquarie University, Sydney
}

\begin{abstract}
This chapter, examining information systems (IS) in New South Wales (NSW) universities, highlights the significance of New South Wales as the most populous state in Australia. Rather than offering a comprehensive coverage of all IS courses in the state, the chapter gives a broad overview of IS in the state's universities while seeking to highlight the distinctive characteristics of some of the universities deemed to have particular significance in the state. The view portrayed is of an environment threatening the continuing existence of IS in some of the state's universities. Again, the condition of IS research in the state's universities is characterised by diversity and limited collaboration.
\end{abstract}

\section{Introduction}

The information and communications technology (ICT) industry is a significant part of the NSW economy, ranked seventeenth in the world according to a NSW government report (NSW Government 2001). This report also suggests that this significance is reflected in some 70 per cent of the top 250 Australian IT head offices being located in New South Wales. There are long-established university programs that support this economy. As New South Wales is the most populous state, it is natural that there are more universities and more programs to report on than in other states. This report will concentrate on those universities that have been most significant in the development of the IS discipline in New South Wales and give outline information for the others. The basis for this selection will be explained in the next section of the report. The universities that are reported on in detail are the University of New South Wales (UNSW), the 
University of Sydney, Wollongong University, the University of Technology, Sydney (UTS), and Charles Sturt University.

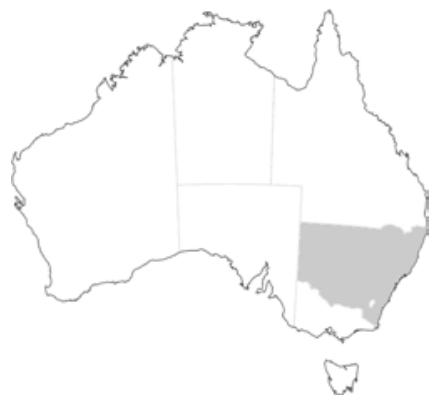

Figure 5.1 Location of New South Wales within Australia

\section{Overview of the IS presence in NSW universities}

As some universities have more than one administrative entity that is concerned with IS, these are shown separately in Table 5.1.

The UNSW has had a historical place in the development of IS in Australia going back to the leadership of Cyril Brookes. This place has wavered over time but the school remains a significant player in IS research and education. The UTS also has a long history of IS that has complemented and competed with the UNSW. Both of these have organisational units with names including IS and the only other such unit is the formal 'discipline' of IS at Wollongong. This alone merits their in-depth treatment. The only other university that is considered in detail is the University of Sydney - for two reasons: first, the relatively recent establishment of a 'discipline group' of IS in the Faculty of Commerce is seen as a strategic move warranting consideration; and second, because of the significant status and historic role of the Department of Computer Science and its IS members. Charles Sturt University has long had IS-related courses and has been a major provider of distance learning. Here we discuss mainly the Riverina operation, which has been associated closely with library studies.

Dealing with the other units in turn, the University of Western Sydney (UWS) had a long-term role going back to data-processing days, but this has been much reduced today. Macquarie University has several IS degrees, including majors in the Bachelor of Business Administration (BBA), but the few IS faculties remain fragmented. Southern Cross University (SCU) has significant distance education enrolments and is a relatively new entrant in the market-place, with some significant innovation. Its influence on the discipline in New South Wales is as yet not large, but the research activity at SCU in particular could establish a future place for it. The University of New England (UNE) and Newcastle University are underdeveloped in terms of IS. We now present an outline of the five identified universities. 
Table 5.1 IS presence in NSW universities

\begin{tabular}{l|l|l|l}
\hline University & Administrative entity & Home faculty & No. of IS academics \\
\hline UNSW & $\begin{array}{l}\text { School of Information } \\
\text { Systems, Technology and } \\
\text { Management }\end{array}$ & Commerce and Economics & 20 \\
\hline UNSW & Group & $\begin{array}{l}\text { Australian Graduate } \\
\text { School of Management } \\
\text { (AGSM) }\end{array}$ & 1 \\
\hline University of Sydney & $\begin{array}{l}\text { Group in School of } \\
\text { Information Technology } \\
\text { (IT) }\end{array}$ & Science & ca. 5 \\
\hline University of Sydney & $\begin{array}{l}\text { Business IS 'Discipline' in } \\
\text { School of Business }\end{array}$ & $\begin{array}{l}\text { Faculty of Business and } \\
\text { Economics }\end{array}$ & 12 \\
\hline UTS & Department of IS & Information Technology & 20 \\
\hline University of Wollongong & $\begin{array}{l}\text { 'Discipline' of IS in School } \\
\text { of Economics and } \\
\text { Information Systems }\end{array}$ & Commerce & 15 \\
\hline UWS & $\begin{array}{l}\text { Group in School of } \\
\text { Computing and } \\
\text { Mathematics }\end{array}$ & Health and Science & ca. 10 \\
\hline Macquarie University & $\begin{array}{l}\text { Group in Department of } \\
\text { Computing }\end{array}$ & $\begin{array}{l}\text { Information and } \\
\text { Communication Sciences }\end{array}$ & ca. 5 \\
\hline Macquarie University & $\begin{array}{l}\text { Group in Department of } \\
\text { Accounting and Finance }\end{array}$ & $\begin{array}{l}\text { Economic and Financial } \\
\text { Studies }\end{array}$ & ca. 3 \\
\hline Macquarie University & Group & MGSM & 1 \\
\hline Charles Sturt University & $\begin{array}{l}\text { Group in School of } \\
\text { Information Studies }\end{array}$ & Science and Agriculture & $10+$ \\
\hline SCU & $\begin{array}{l}\text { Group in School of } \\
\text { Multimedia and IT }\end{array}$ & $\begin{array}{l}\text { Commerce and } \\
\text { Management }\end{array}$ & 12 \\
\hline University of Newcastle & $\begin{array}{l}\text { Group in School of } \\
\text { Design, Communication } \\
\text { and IT }\end{array}$ & Science and IT & ca. 3 \\
\hline & & & \\
\hline
\end{tabular}

\section{The UNSW}

The School of Information Systems, Technology and Management (SISTM) has a long and varied history (there was a Department of Information Systems in the early 1980s). Today, it is placed within the Commerce Faculty but does not have a core unit in that faculty's flagship BComm program. It has its own BSc in IS as well as a major in IS available in many degrees. High entrance scores are required in all programs. The distinctive BIT degree has industry training (which entails students spending time working in industry during the degree studies), industry-funded student scholarships and includes an Honours year. A Master's degree in IS is being established but there is support teaching for other Masters degrees.

The school has long been active in research, with strong performances in quantitative aspects of IS, especially in the 1980s and early 1990s. There have also been strong performances in major research grants and doctoral student completions. With the appointment of a new head of school (Dubravka Cecez-Kecmanovic), qualitative research methods in IS are likely to become more prominent. Highly rated IS research in management areas is conducted at the 
Australian Graduate School of Management (AGSM), but there is no collaboration with SISTM. SISTM is seen to be distinct from computer science within the UNSW.

\section{The University of Sydney}

As a traditional university, the University of Sydney has until recently located IS primarily in computer science, with a Sybase Chair in Information Systems appointed there in 1998-although the position is now called 'language technology', reflecting the interests of the incumbent. Other areas, such as librarianship and informatics (in the Faculty of Arts), have developed independently. The major in IS offers the same units to various degrees. There are now some 30 students (out of 100) doing an IS project in their BSc Honours degree - the largest honours group in New South Wales. The computer science department is developing a masters in IT that will have an IS major.

In contrast, the newly established business IS 'discipline' (one of 10) in the Faculty of Commerce teaches the IS core to some 1000 students in the BComm program, aiming to recruit them to the IS major. Students in the accounting stream take additional IS units, also in MBus and MComm. A new MBusIS degree started in 2006. The establishment of this discipline was seen as a strategic move by the dean, to provide visibility and to promote interdisciplinary research. Five research areas have been selected to build strength in the group.

There is not much visibility of IS (in either incarnation) in the wider university community.

\section{The UTS}

From the days of the NSW Institute of Technology - the UTS predecessor institution-vocationally oriented programs have been developed. At the undergraduate level, all courses were in either part-time or 'sandwich' mode, requiring students to spend usually one year in suitable paid employment before graduation. In response to an increasing number of international students and the decline of employment opportunities, industrial experience became optional in 2002, and the number of students graduating with work experience has gradually decreased. To some extent this experience is now 'simulated' in a large group-systems development project.

Since 1968, computing has been taught in a variety of science-oriented faculties; a second Business Information Systems group developed within the Faculty of Business. These two groups were brought together in about 1980 in a Faculty of Mathematical and Computer Sciences; this faculty became the Faculty of Information Technology in 2000. A number of conflicts between the 'science' and 'business' groups in the 1980s are still having an impact on the faculty. In the Faculty of Information Technology, IS was established as one of three 
departments but with limited autonomy. As a matter of policy, all faculty courses are interdepartmental, as the 'integration' of computer science and IS is seen as a key strength of the UTS. In the late 1990s, the faculty grew rapidly and was a strong contributor to UTS income, but the faculty is now suffering from the reduced enrolments in IT common across the sector. This has impacted particularly on the IS department as it had a large number of students from the Faculty of Business enrolled in IS majors. In terms of research profile and general visibility within the university, the IS department remains relatively weak alongside the other departments. Research in the IS department has taken a lower profile historically and, even today, the proportion of staff without doctorates is comparatively high.

\section{The University of Wollongong}

The IS discipline has some 400 equivalent full-time students units (EFTSU) at the moment, making it probably the largest outside Sydney; there are undergraduate and graduate programs. Its history goes back to 1984 when an IS group from the then Wollongong Institute joined the commerce faculty. In 1991, a Faculty of Informatics was created but IS stayed with commerce. Programs were supported by the local presence of BHP, one of Australia's largest companies, and some research success was achieved in the 1990s. Currently, the discipline is perceived as suffering somewhat from the increasing proportion of overseas students, difficulties in attracting research students and lack of distinctive recognition within the university.

\section{Charles Sturt University, Riverina}

Charles Sturt is a multi-campus regional university, so the administrative position and visibility of IS depends to a large extent on cross-campus structure and politics. At present, IS lies within the Faculty of Science and Agriculture, which controls staffing, major funding and course and subject design. At Wagga Wagga, on the other hand, arrangements have remained fairly stable, with IS as a 'discipline area' in the School of Information Studies. In the past, this placement has encouraged an emphasis on the 'information science' aspects of IS (an aspect largely ignored elsewhere) but this specialisation is diminishing.

As a regional university, Charles Sturt has a majority of students studying in distance mode, and has good relationships with the community, TAFE and local business (which is not strong). Research projects are mainly individual, and a number of full-time academics are currently enrolled in PhDs. Collaboration tends to be with universities in the nearby Australian Capital Territory rather than with the rest of New South Wales. Researchers do not identify (or feel the need to identify) particularly with IS as such. There is a feeling that regional universities are (for political reasons) less threatened than others by fluctuations in student demand and research fashion. 


\section{Results}

The next sections summarise and discuss the responses under the headings adopted by the survey instrument that is presented in Ridley (2006).

\section{Relative size of IS presence}

Students undertaking strongly identified IS undergraduate degrees can be found only at the UNSW. The UTS has an IT degree with IS as an 'equal' component, and a cross-faculty business/computing degree. These universities also offer a variety of majors in non-IS programs. This format - majors in other programs - is the bread and butter of IS in all the other universities. The size of the IS presence therefore depends on the university's enrolment in the core programs that offer the majors and the extent of compulsory subjects in those programs. Large accounting programs mean that many students will need to do IS and larger staff numbers are entailed. With more than 1000 students in commerce at the University of Sydney, a larger IS unit is created.

Another characteristic is the fragmentation of IS academics across departments or faculties.

\section{Administrative placement of IS}

With the growth of enrolments in commerce in the past 20 years, there has been some advantage to those IS units that are placed in that faculty; however, a variety of locations, especially science and computer science, persist. Most IS groups remain as ad hoc or informal groups within larger departments.

\section{Local contingencies}

It is noteworthy that when asking participants about 'local contingencies', responses reflect 'very local' issues, such as organisational politics, nearby employers and competitors. There were no 'NSW' issues that came up-for example, Wollongong's support from BHP, alternative perspectives at the UTS and the UNSW, or faculty rules at Sydney.

\section{IS as a separate field}

While the four universities highlighted had some structural recognition of IS as a separate field, it was held widely that this did not extend to the wider university communities. Indeed, the interviewees would be challenged to agree on a definition of IS that was mutually satisfactory. For example, the International Conference on Information Systems (ICIS) and the Australasian Conference on Information Systems (ACIS) were not universally agreed on as central conferences. The fragmented state of IS at Macquarie University (an ad hoc IS group in computing, an accounting IS group in accounting, information management taught in statistics and IS management in the management school) is symptomatic. 


\section{Distinctive IS curricula}

The language technology emphasis in one group at the University of Sydney is the most distinctive. Support classes within commerce programs are possibly the least distinctive across universities. The UTS has systematically innovated with specialist programs over the years, especially at the Masters level. 'Cooperative' programs - that is, with an industrial training component-are offered only at the UTS and the UNSW.

\section{Distinctive features of IS research}

The IS group at the UNSW has been productive for a long period, particularly in quantitative aspects (some would describe this as software engineering). This emphasis has declined and qualitative research is growing there. Each group at the University of Sydney is pursuing independent research strategies, with the scam-detection project of Jon Patrick very large, although not labelled as IS. At the UTS, Igor Hawryszkiewycz leads a large continuing project on collaborative systems software, but few full-time IS staff are involved in this project. Ernest Edmonds' new 'creativity and cognition' studio is under the IS umbrella, but works with computer scientists as much as with other IS academics. Large research projects in IS are otherwise few in number. Research activity tends to be fragmented and diverse.

Small research groups, especially of doctoral students, at the AGSM and Macquarie Graduate School of Management (MGSM) have existed without undergraduate programs to build the staff numbers to critical mass.

\section{Perceptions of other universities}

The founding roles of the UNSW, UTS and Sydney were recognised widely although there was also some recognition of interstate universities and researchers.

\section{Key people in the region}

In the 'round up of the usual suspects', members of the Australian Council of Professors and Heads of Information Systems (ACPHIS) and ACIS regulars were the most widely cited. Ron Weber has been influential outside Australia - perhaps more than inside. Dubravka Cecez-Kecmanovic and Steve Elliott are in significant strategic positions in New South Wales at the moment.

\section{Vignette-Igor Hawryszkiewycz}

Professor Igor Hawryszkiewycz is head of the Department of Information Systems at the UTS, where he is responsible for teaching and research in the department. He completed a BE and ME degrees in electrical engineering at the University of Adelaide, and a $\mathrm{PhD}$ at the Massachusetts Institute of Technology. His expertise is in the area of design of information systems. He has developed 
methods for the design of systems that have been reported in more than 150 publications.

His widely adopted text in the mid-1980s on database analysis and design represents a significant early contribution to IS in Australian universities, as does his text on systems analysis and design, first published in 1987. This latter book was well accepted internationally, and was translated into several languages and offered in five editions. Later books, on relational database design (1990) and the design of networked enterprises (1997), have added to Hawryszkiewycz's standing as an IS researcher and educator.

Hawryszkiewycz was an important figure in the establishment, in 1989, of a national conference in IS. Through the early years of the ACIS he was a member of the conference standing committee.

Before joining the UTS, Hawryszkiewycz was a principal lecturer in IS at the University of Canberra and, before that, a research engineer at Telecom Australia and a senior systems officer at the Telecom Information Systems Branch.

He has also been:

- a visiting professor at the University of Sydney

- a visiting professor at the UNSW

- a visiting professor at the University of Maryland, College Park

- a visiting professor at the University of Vienna

- a visiting scientist at the FAW in the University of Ulm, Germany

- a visiting scientist at GMD, Bonn, Germany

- a visiting scholar at Tilburg University in the Netherlands

- a research fellow at the British Telecom Laboratories in Martlesham, UK.

His current emphasis is on the design of knowledge-based collaborative systems that are required to support process agility in the increasingly competitive environment. This focuses on developing requirements for collaborative systems and supporting them with technology that integrates collaboration into the business process. His work on collaboration has included research as well as industrial applications as, for example, setting up business networks or health research planning, as well as developing a workspace system.

Hawryszkiewycz is a member of the Australian Research Council (ARC) Research Network in Enterprise Information Infrastructure. Within this network, he is participating in a program on technology adoption and impact and is a senior member of a task force investigating major issues related to service computing and business process management. 


\section{Vignette-Dubravka Cecez-Kecmanovic}

Dubravka Cecez-Kecmanovic is Professor of Information Systems and Head of Information Systems, Technology and Management in the Australian School of Business at the UNSW.

Cecez-Kecmanovic Dubravka earned her BSc in electrical engineering at the University of Sarajevo (1970), MSc in system sciences and IS at the University of Belgrade (1974) and a PhD in IS at the University of Ljubljana (1979). Until 1992, she was with the Informatics Department, Faculty of Electrical Engineering, University of Sarajevo, where she held positions as the head of the IS department, associate dean and dean of the faculty, among others. Since arriving in Australia in 1993, she has held the positions of Professor and Head of School of Information Systems and Management Science, and Deputy Dean of the Faculty of Commerce and Administration, Griffith University, Brisbane; Pro-Vice-Chancellor, Research and Consultancy, and Professor and Founding Chair in Information Systems at the UWS, Hawkesbury. She has been with the UNSW since January 2002.

Cecez-Kecmanovic has published in the field of social systems of information and government IS, decision support systems, web-enhanced cooperative learning and teaching and electronically mediated work and communication. Her recent research interests include the sense-making theory of knowledge as a foundation to study information and knowledge systems in organisations; evolutionary approaches to organisations and IS; autopoietic views of IS organisation relationships; IS and organisational learning; electronic democracy and the social aspects of electronic commerce. Cecez-Kecmanovic's major contribution has been to critical theory-informed IS research, including theoretical, methodological and empirical studies, for which she has been recognised internationally. Due largely to her contribution to the development and promotion of the critical approach to IS research, Australian and British researchers have together been leading the critical research project in the IS discipline.

Her major awards include Excellence in Research and Development from the University of Sarajevo (1988), Woman (Academic) of the Year 1989 (in the former Yugoslavia) and Research Excellence Award from the UWS (2000). In 2006, Cecez-Kecmanovic and her co-author, Marius Janson from the University of Missouri, St Louis, were awarded the Emerald Literati Network 2006 Award for Excellence for their paper 'Making sense of e-commerce as a social action' as the best paper published in the Information Technology \& People journal.

\section{Conclusion}

The already fragmented condition of IS in most universities means that with further reductions in undergraduate recruitment their positions will not improve and could deteriorate further. In the view of the authors, the strong candidates for survival and prosperity are SISTM at the UNSW and Business IS at the 
University of Sydney. The chasing pack is led by the Department of Information Systems at the UTS and the IS discipline at Wollongong, which face difficulties at the moment but do have the critical mass to move forward, if the way is clear. Postgraduate specialist programs remain strong at the UTS.

Research is characterised by almost no cross-institutional cooperation and little within institutions. The 'changing of the guard' at the UNSW and the University of Sydney could bring about revivals. The problem will be, however, to avoid the lost opportunities of the 1970s. New South Wales (and Sydney in particular) had at least two institutions with plenty of highly employable undergraduate students, the respect of the IT industry and other institutions, and proximity to a large part of the Australian IT industry for support and research opportunities, yet IS in the institutions failed to develop an identity or a presence. It can be argued that this was due partly to a premature desire to define a discipline. Elias (quoted in Ridley 2006) suggests that modelling low-status on high-status disciplines is bound to fail. The moves suggested by Ridley (2006) for establishing a discipline will, if pursued by individuals or specialised research groups, work against the establishment of a broadly supported discipline. Individual prestigious reputations are established at the expense of wide collaboration, and standard research methods and unique symbol systems are used to exclude rather than enrol. Information systems - and perhaps all new disciplines - defines itself by what it is not, particularly 'not computer science'. It is easy for those outside a developing prestigious group to think 'but that's not really IS'. The drive for academic recognition, particularly in the current university research climate, can also damage relations with industry-relations that are vital to the identity of IS. The question is how can we build a 'discipline that isn't a discipline'?

\section{References}

NSW Government 2001, Skilling People for an Information Society, Office for ICT, NSW Government, viewed March 2006, <http://www.oict.nsw.gov.au/pdf/3.4.1-ICT-Skills.pdf>

Ridley, G. 2006, 'Characterising information systems in Australia: a theoretical framework', Australasian Journal of Information Systems, vol. 14, no. 1, pp. $141-62$.

\section{Addendum: another perspective on the IS discipline in NSW universities}

David Wilson, Faculty of Information Technology, University of Technology, Sydney

The ICT market in Australia is one of the largest in the world, rated in the top three in the Asia-Pacific and eleventh in the world (CeBit 2006). Australia's 
expenditure on ICT is between 4.6 per cent (Australian Information Industry Association and federal government reports) and 6.4 per cent of GDP (CeBit 2006), placing Australia ahead of countries such as the United Kingdom, Canada, China and Japan. New South Wales represents a significant proportion of this market, as it is home to 76 per cent of Australia's ICT regional headquarters and provides employment to more than 120000 people - about 41 per cent of the Australian ICT total (NSW DSRD 2007). New South Wales accounts for 42 per cent of ICT businesses and 47 per cent of telecommunications services (NSW DSRD 2007). New South Wales leads all other Australian states and territories in ICT research capabilities, being the headquarters of five national centres of excellence in ICT-related research fields, two major national research facilities and three cooperative research centres, as well as accounting for 43 per cent of the business expenditure on ICT services research and development in Australia (NSW DSRD 2007).

The ICT industry is changing and exhibits a shift from a techno-centric focus with technology priorities to a business-centric focus with business priorities where client-facing capabilities allied with business and project management skills are critical (Abraham et al. 2006; Zwieg et al. 2006). This represents a shift from a technical computer science and software engineering focus to a business IS focus. Information systems professionals are now required to possess business domain knowledge and project management skills and to have the ability to work well with clients and colleagues to solve business problems; the emphasis is on the client-facing skills of analysis and design enhanced with good communication skills, functional area process knowledge and industry knowledge (Abraham et al. 2006). Information systems professionals will be versatile as they assume numerous new roles, assignments and experiences (Morello and Libman 2005). This view is supported by chief information officers (CIOs), who identify ineffective communication with IS as the top inhibitor of alignment between business and IS (Luftman et al. 2005). Zweig et al. (2006) identified that, in the past, technically skilled early career IS professionals transformed themselves into mid-career professionals with strong business and project management skills through experience gained over many years. In the twenty-first century, this change needs to be effected more rapidly and this will require changes in university curricula, career paths and the continued development and training of IS professionals. Zweig et al. (2006) conclude that, although the balance of technical, business and project management skills is unlikely to be found in a fresh undergraduate, CIOs want to hire graduates with foundation technical skills complemented by business knowledge and project skills and the ability to work closely with non-technical departments and users.

In summary, New South Wales occupies a prominent position in a significant industry sector that is experiencing a skills shortage, yet the prognosis in the NSW chapter of this book is generally one of doom and gloom. NSW IS university 
departments are well positioned to produce graduates with the business-centric focus where client-facing capabilities allied with business and project management skills are in demand, yet the numbers of applications and enrolments are, in general, falling. There appears to be no one simple answer for this, but possible reasons that have been advanced include:

- fears that the improvement is a 'spike' and will not be sustained

- a natural lag in students responding to the changed jobs situation; things could improve in 2008

- despite the improvement, IS/ICT has lost its 'golden glow'; it is no longer a discipline of choice

- the stereotype of IS/ICT being dominated by male 'nerds' is strong and puts off potential applicants

- current school students are computer literate and therefore do not appreciate the career opportunities in the industry

- IS/ICT does not appeal to the aspirations of 'Generation $\mathrm{Y}^{\prime}$.

Whatever the reason - and in reality all these factors might contribute to the issue - it is clear that IS (and ICT) has lost credibility. The Y2K 'fizzer', the dotcom bust, the trend towards offshoring and a poor understanding of the IS industry among the general public have all contributed to decreased interest in IS-related careers among young people. The immediate issue is to promote IS as an interesting and rewarding career option for young people and to return the discipline to being one of choice. NSW IS university departments can be in the vanguard of this recovery.

\section{References}

Abraham, T., Beath, C., Bullen, C., Gallagher, K., Goles, T. K. K. and Simon, J. 2006, 'IT workforce trends: implications for IS programs', Communications of the Association for Information Systems, vol. 17, pp. 1147-70.

CeBit Australia 2006, Australian ICT Industry, viewed June 2007, <http://www.cebit.com.au/main/CeBIT/australian_ict_industry.asp>

Luftman, J., Kempaiah, R. and Nash, E. 2005, 'Key issues for IT executives 2005', MIS Quarterly Executive, vol. 5, no. 2, pp. 81-99.

Morello, D. and Libman, P. 2005, The IT Professional Outlook: Where Will We Go From Here?, Paper presented to Gartner Symposium ITxpo, Cannes, November 2005.

NSW Department of State and Regional Development (NSW DSRD) 2007, Industry Profiles: Information and Communications Technology, viewed June 2007, $<$ http://www.business.nsw.gov.au/industry/ict/> 
Zwieg, P., Kaiser, K. M., Beath, C. M., Bullen, C., Gallagher, K. P., Goles, T., Howland, J., Simon, J. C., Abbott, P., Abraham, T., Carmel, E., Evaristo, R., Hawk, S., Lacity, M., Gallivan, M., Kelly, S., Mooney, J. G., Ranganathan, C., Rottman, J. W., Ryan, T. and Wion, R. 2006, 'The information technology workforce: trends and implications 2005-2008', MIS Quarterly Executive, vol. 5, no. 2, pp. 101-8. 